\title{
Studi Perbandingan Disolusi In-Vitro pada Formula Tablet Levofloksasin Immediate-Release Menggunakan Variasi Kadar Disintegran Sodium Starch Glycolate
}

\author{
Comparative In-Vitro Dissolution Study of Levofloxacin Formula Immediate- \\ Release Tablets Using Various Concentration of Sodium Starch Glycolate as \\ Disintegrant
}

\author{
Shesanthi Citrariana, Endang Lukitaningsih, Akhmad Kharis Nugroho* \\ Fakultas Farmasi, Universitas Gadjah Mada \\ Corresponding author: Akhmad Kharis Nugroho: Email: a.k.nugroho@ugm.ac.id \\ Submitted: 22-08-2019 Revised:09-09-2019 Accepted: 11-09-2019
}

\begin{abstract}
ABSTRAK
Levofloksasin merupakan antibiotik yang digunakan dalam terapi Community Acquired Pneumonia (CAP) dengan prevalensi cukup tinggi di Indonesia. Sodium starch glycolate (SSG) merupakan eksipien yang berfungsi sebagai disintegran. SSG direkomendasikan dalam formula tablet dengan konsentrasi 1-4\% karena konsentrasi yang lebih tinggi dapat mengurangi kemampuan disintegrasinya. Kinetika pelepasan obat memiliki nilai yang sangat penting dalam pengembangan dan kontrol kualitas obat. Perubahan kualitatif dan kuantitatif eksipien dalam formula dapat mengubah kinetika pelepasan dan kinerja in-vivo. Peneliltian ini bertujuan untuk melakukan studi perbandingan kinetika pelepasan obat pada tablet levofloksasin yang diformulasikan menggunakan berbagai konsentrasi SSG. Hasil penelitian ini memperlihatkan bahwa konsentrasi SSG 1,33-5,33\% dalam formula tidak memberikan perbedaan model kinetika pelepasan obat. Hal ini terlihat dari nilai f1 $(3,12-8,50)$ dan f2 $(56,16-77,43)$ yang berada pada rentang kriteria. Tablet levofloksasin Immediate-release (IR) yang diformulasikan, mengikuti pemodelan First-Order kinetik dengan kriteria nilai R2_adj tertinggi, MSE dan AIC terkecil, serta MSC terbesar dibandingkan dengan model kinetika lainnya. Pemodelan menggunakan Korsmeyer-Peppas memperlihatkan bahwa mekanisme transport dari tablet levofloksasin mengikuti persamaan Fickian semu $(\mathrm{n}<0,5)$ sehingga menggambarkan pelepasan obat dari matriks non-swellable.
\end{abstract}

Kata kunci: levofloksasin; tablet; sodium starch glycolate; pemodelan kinetika

\section{ABSTRACT}

Levofloxacin is an antibiotic used to treat Community Acquired Pneumonia (CAP) which has a high prevalence in Indonesia. Sodium starch glycolate (SSG) is an excipient used as disintegrant. SSG is recommended in tablet formulas with a concentration range of 1-4\% because higher concentrations can reduce the ability of disintegration. The drug kinetic has a very important role in the development and quality control of drugs. Qualitative and quantitative changes of excipients in formulas can influence drug release kinetics and in-vivo performance. This study aims to compare the kinetics of drug release on levofloxacin tablets formulated using various SSG concentrations. The results of this study showed that SSG concentrations ranging from 1.33 to $5.33 \%$ in formulas did not give a difference in the kinetics of levofloxacin tablet release. This can be seen from the values of $\mathrm{f} 1$ $(3,12-8,50)$ and $\mathrm{f} 2(56,16-77,43)$. Levofloxacin Immediate-release (IR) tablets, followed kinetic FirstOrder modeling with the highest R2_adj, the smallest MSE and AIC, and the largest MSC compared to other kinetics models. Modeling using Korsmeyer-Peppas shows that the transport mechanism of levofloxacin follows a quasi Fickian equation $(\mathrm{n}<0.5)$ thus describing the release of drugs from a nonswellable matrix.

Keywords: levofloxacin; tablet; sodium starch glycolate; kinetic drug release

\section{PENDAHULUAN}

Levofloksasin merupakan antibiotik golongan fluoroquinolon generasi ketiga yang digunakan dalam terapi utama pada infeksi saluran pernapasan kronis terutama pada penyakit Community Acquired Pneumonia (CAP) (Destache dkk., 2001). Di Indonesia serta beberapa negara berkembang lain seperti India, 
Tabel I. Formula Tablet Levofloksasin

\begin{tabular}{lccccc}
\hline Nama Bahan & A & B & C & D & E \\
\hline Levofloksasin (mg) & 60 & 60 & 60 & 60 & 60 \\
Laktosa (mg) & 79,5 & 78 & 82,5 & 76,5 & 81 \\
PVP K-30 (mg) & 0,5 & 0,5 & 0,5 & 0,5 & 0,5 \\
SSG (mg) & 5 & 6,5 & 2 & 8 & 3,5 \\
Talkum (mg) & 4,5 & 4,5 & 4,5 & 4,5 & 4,5 \\
Mg. stearat (mg) & 0,5 & 0,5 & 0,5 & 0,5 & 0,5 \\
\hline
\end{tabular}

Nepal, dan Bangladesh memiliki prevalensi CAP yang cukup tinggi (Shrestha dkk., 2012).

Eksipien adalah bahan tambahan yang berfungsi mengatur biopharmaceutical performance. Sodium Starch Glycolate (SSG) merupakan eksipien yang berfungsi mengatur tablet hancur dalam saluran cerna (Niazi, 2004). Perbedaan disintegran berpengaruh terhadap absorpsi obat terutama berkorelasi pada efflux obat di sel epitel saluran cerna dalam percobaan in-vitro (Gerber dkk., 2018). SSG merupakan cross linked starch memiliki kemampuan swelling 7-12 kali dalam waktu <30 detik. (Jaimini dkk., 2013). Konsentrasi SSG yang disarankan dalam formula tablet adalah 1-4\%. Penggunaan SSG dengan konsentrasi yang lebih tinggi karena dapat menyebabkan proses gelling dan akan kehilangan fungsinya sebagai disintegran (Pahwa dan Gupta, 2011).

Disolusi dan pelepasan obat adalah fenomena penting untuk bentuk sediaan padat seperti tablet, kapsul dan bentuk sediaan semipadat seperti krim, salep, dan implan yang mengantarkan obat selama periode waktu tertentu berkisar dari jam, minggu, dan tahun (Ramteke dkk., 2014). Ada beberapa model kinetik yang menggambarkan pelepasan obat dari bentuk sediaan. Perubahan kualitatif dan kuantitatif eksipien dalam formula dapat mengubah kinetika pelepasan dan kinerja invivo. Dengan demikian, pemodelan kinetika dari pelepasan obat memiliki peran yang sangat penting dalam proses pengembangan formula sediaan obat (Paarakh et al., 2018).

Peneliltian ini bertujuan untuk melakukan perbandingan kinetika pelepasan obat terhadap tablet levofloksasin Immediaterelease (IR) yang diformulasikan menggunakan berbagai konsentrasi SSG. Pemodelan kinetika dari profil disolusi in-vitro tablet levofloksasin menggunakan DD Solver add in pada MS.Excel.

\section{METODOLOGI Bahan}

Aquabidest (PT. Ikapharmindo Putramas), aquadest, asam asetat (E. Merck, Germany), $\mathrm{HCl} 37 \%$ (E. Merck, Germany), talkum, levofloksasin (diperoleh dari PT. Kimia Farma, Tbk.), laktosa, SSG (Gujarat Overseas Inc., India), magnesium stearat (Faci Asia Pacific Pte., Ltd., China), PVP K-30 (Nanhang Industrial Co., Ltd., China).

\section{Alat}

Mesin tablet (single punch merk Korsch $($ ), hardness tester (Erweka), friability tester (Erweka), neraca analitik (Mettler Toledo $囚$ ), disintegration tester (Erweka Z.T.21), alat uji disolusi USP tipe II (Erweka DT-700®), spektrofotometer (Hitachi® U-2810).

\section{Jalannya Penelitian}

Formula Tablet Levofloksasin

Penentuan formula dilakukan dengan variasi kadar bahan penghancur SSG. Batas atas jumlah disintegran yang digunakan dalam formula adalah $2 \mathrm{mg}(1,33 \%)$ dan batas bawah adalah $8 \mathrm{mg}$ (5,33\%) (Qureshi dkk., 2016). Bahan pengisi akan menjadi eksipien yang mengalami penyesuaian jumlah untuk mempertahankan agar bobot tablet levofloksasin tetap yaitu sebesar $150 \mathrm{mg}$. Formula tablet levofloksasin dapat dilihat pada (Tabel I).

\section{Proses Granulasi Basah}

Levofloksasin dan laktosa dicampur hingga homogen, ditambahkan larutan PVP K30 (2\% dalam aquadest) hingga diperoleh konsistensi campuran yang diinginkan.

Hasil campuran kemudian dilakukan ayak basah menggunakan mesh-16 untuk selanjutkan dikeringkan pada oven dengan 
suhu $40^{\circ} \mathrm{C}$ selama 18 jam. Hasil pengeringan kemudian diayak kering menggunakan mesh-20.

\section{Proses Pembuatan Tablet Levofloksasin \\ Pengempaan Tablet}

Granul yang telah dibuat kemudian dilakukan pencampuran dengan SSG, talkum, dan magnesium stearat hingga homogen. Tablet dikempa dengan mesin cetak single punch, diameter punch $7 \mathrm{~mm}$. Setelah tablet selesai dikempa maka selanjutnya akan diuji sifat fisik, kadar, dan disolusinya.

\section{Pengujian Sifat Fisik \\ Keragaman Bobot}

Sebanyak 20 tablet ditimbang, kemudian dihitung bobot rata-ratanya. Tablet tersebut lalu ditimbang kembali satu persatu dan dibandingkan dengan bobot rata-rata tabletnya sehingga diperoleh nilai penyimpangan bobot tablet (USP 30-NF 25, 2007).

\section{Kekerasan Tablet}

Sebanyak 10 tablet diambil secara acak kemudian diuji kekerasannya dengan hardness tester. Nilai rata-rata kekerasan 10 tablet dihitung berserta nilai standar deviasinya (USP 30-NF 25, 2007).

Kerapuhan Tablet

Sebanyak 20 tablet levofloksasin dibersihkan terlebih dahulu lalu ditimbang bobotnya. Seluruh tablet dimasukan dalam fiblator dan alat dijalankan selama 4 menit dengan kecepatan $25 \mathrm{rpm}$. Setelah selesai tablet dibersihkan kembali dan ditimbang (USP 30-NF $25,2007)$.

\section{Waktu Hancur}

Sebanyak 6 tablet diambil secara acak kemudian dimasukan kedalam tabung dari keranjang alat disintegration tester dan dimasukkan satu cakram pada tiap tabung. Media yang digunakan berupa air bersuhu $37^{\circ} \pm 2^{\circ} \mathrm{C}$. Waktu hancur tablet dihitung mulai saat keranjang tercelup sampai semua tablet hancur secara sempurna (Anonim, 2014).

Pengujian Kadar Tablet

Tablet levofloksasin ditimbang dan dilarutkan $\mathrm{HCl} 0,1 \mathrm{~N}$ dalam labu $25 \mathrm{ml}$ (larutan stok) kemudian dihomogenkan dengan vortex selama 1 menit. Larutan levofloksasin disaring dengan kertas watman dan dilakukan pengenceran 1000 kali dengan memipet sebanyak $25 \mu \mathrm{L}$ larutan stok dan ditambahkan larutan $\mathrm{HCl}$ 0,1 N dalam labu $25 \mathrm{ml}$ hingga tanda batas. Kemudian dilakukan pembacaan pada spektrofotometer UV pada $\lambda=295 \mathrm{~nm}$.

\section{Pengujian Disolusi In-Vitro}

Uji disolusi menggunakan metode USP 30-NF 25 tipe II (Tipe Dayung) (supplement Pending Monographs Guideline, monograph belum tertera pada farmakope Indonesia edisi V) dengan medium $900 \mathrm{~mL} \mathrm{0,1} \mathrm{N} \mathrm{HCl} \mathrm{pada} \mathrm{suhu}$ $37 \pm 0,5^{\circ} \mathrm{C}$ dan kecepatan $100 \mathrm{rpm}$. Setelah 10 , 20, 30, 40, 50 dan 60 menit, 5 mL larutan ditarik dan diganti dengan jumlah 0,1 $\mathrm{N} \mathrm{HCl}$ larutan yang sama. Sampel larutan disolusi kemudian dianalisis dengan menggunakan spektrofotometer UV pada $\lambda=295 \mathrm{~nm}$ (Bhavanam dkk., 2010).

\section{Analisis Data Disolusi In-Vitro}

Perangkat lunak add-in untuk Microsoft Excel (DD solver) digunakan untuk perhitungan statistik serta pemodelan kinetika profil disolusi yang diperoleh. Profil disolusi masing-masing formula akan dibandingkan dengan menggunakan model independent method dan model dependent method.

\section{Model Independent Method}

Menurut Food and Drug Administration (FDA) untuk perbandingan tablet IR, direkomendasikan menggunakan faktor perbedaan (f1, persamaan 1) dan faktor kesamaan (f2, persamaan 2). Jika nilai f1 adalah antara 0-15, dan nilai f2 antara 50 dan 100, profil yang diamati dapat dianggap serupa (Costa dan Sousa Lobo, 2001).

$f 1=\frac{\sum_{t=1}^{n}[R t-T t]}{\sum_{t=1}^{n} R t} \times 100$

$f 2=50 x \log \left\{\left|1+\left(\frac{1}{2}\right) \sum_{t=1}^{n} R t-T t\right|\right\}^{-0,5} x 100$

Keterangan: $\mathrm{n}$ : banyaknya sampel pada penelitian; Rt : \% kumulatif disolusi formula 
Tabel II. Sifat Fisik Tablet Levofloksasin

\begin{tabular}{llccc}
\hline & Keragaman Bobot (mg) & Kekerasan (kg) & Kerapuhan (\%) & Waktu hancur (menit) \\
\hline A & $153,85 \pm 3,43$ & $4,61 \pm 0,41$ & 0,28 & 5,03 \\
B & $155,90 \pm 1,86$ & $5,35 \pm 0,53$ & 0,37 & 4,18 \\
C & $152,05 \pm 4,43$ & $5,08 \pm 0,68$ & 0,43 & 6,40 \\
D & $150,75 \pm 3,12$ & $4,38 \pm 0,36$ & 0,55 & 4,16 \\
E & $149,05 \pm 1,53$ & $4,25 \pm 0,48$ & 0,33 & 4,37 \\
\hline
\end{tabular}

Tabel III. Kadar Levofloksasin dalam Tablet

\begin{tabular}{ll}
\hline & Rentang Kadar (\%) \\
\hline A & $102,928 \pm 4,126$ \\
B & $96,738 \pm 4,206$ \\
C & $103,261 \pm 4,748$ \\
D & $97,261 \pm 2,141$ \\
E & $99,500 \pm 4,843$ \\
\hline
\end{tabular}

yang menjadi pembanding tiap waktu; $\mathrm{Tt}: \%$ kumulatif disolusi formula yang dibandingkan tiap waktu.

\section{Model Dependent Method \\ Pada penelitian ini model kinetika} pelepasan obat yang digunakan adalah Zero Order, First Order, Higuchi, Hixson-Crowell, dan Korsmeyer-Peppas model. Parameter yang digunakan untuk menentukan model terbaik meliputi: koefisien determinasi ( $\left.\mathrm{R}^{2} \_\mathrm{adj}\right)$, mean square error (MSE), Akaike Information Criterion (AIC) dan Model Selection Criterion (MSC) (Todorović dkk., 2018).

Koefisien determinasi ( $\mathrm{R}^{2}$ adj) dihitung berdasarkan jumlah dari parameter dan memiliki nilai 1 pada model.

Ketika terdapat penurunan nilai maka terjadi over fit pada model. Penentuan koefisien determinasi menggunakan persamaan 3 :

$R^{2}$ adj $=1-\frac{n-1}{n-p} \times 1-R^{2}$

Keterangan: $\mathrm{n}$ : jumlah data disolusi; $\mathrm{p}$ : jumlah parameter dalam model.

Akaike Information Criterion (AIC) dihitung berdasarkan pada volume data dan besarnya Weighted Sum of Squares (WSS). Berdasarkan pada AIC, model yang memiliki nilai paling kecil menunjukan fitting yang terbaik. Nilai AIC mengikuti persamaan 4 (Costa dan Sousa Lobo, 2001):
$A I C=n x \ln (W S S R)+2 x p$

Keterangan: $\mathrm{n}$ : jumlah data disolusi ; $\mathrm{p}$ : jumlah parameter dalam model; WSS : weighted sum of squares.

Model Selection Criterion (MSC) dihitung berdasarkan persamaan 5. MSC pada model memiiliki nilai yang lebih menunjukan fitting terbaik. Niali MSC lebih dari 2 mengindikasikan model kinetika terbaik (Zhang dkk., 2010).

$$
M S C=\ln \frac{\sum_{i=1}^{n} w i x\left(y i_{o b s}-\bar{y} i_{o b s}\right)^{2}}{\sum_{i=1}^{n} w i x\left(y i_{o b s}-\bar{y} i_{p r e}\right)^{2}}-\frac{2 p}{n}
$$

Keterangan: $\mathrm{n}$ : jumlah data disolusi; $\mathrm{p}$ : jumlah parameter dalam model; $\mathrm{w}_{\mathrm{i}}$ : weighting factor (1); yi_obs : data observasi i dengan nilai y; $y_{i}$ pre : data presiksi i dengan nilai y; $\bar{y}_{\text {_obs }}$ : nilai ratarata data observasi y; $\bar{y}_{\text {_pre }}$ : nilai rata-rata data prediksi y.

\section{HASIL DAN PEMBAHASAN \\ Sifat Fisik Tablet Levofloksasin}

Hasil pengujian sifat fisik tablet levofloksasin dapat dilihat pada Tabel II. Tablet levofloksasin semua formula memiliki keseragaman bobot yang baik dan tidak ada satupun tablet menyimpang $>10 \%$ dari bobot rata-ratanya. Kekerasan tablet berada pada kisaran 4-6 dan kerapuhan $<1 \%$. Waktu hancur tablet levofloksasin dengan konsentrasi SSG 


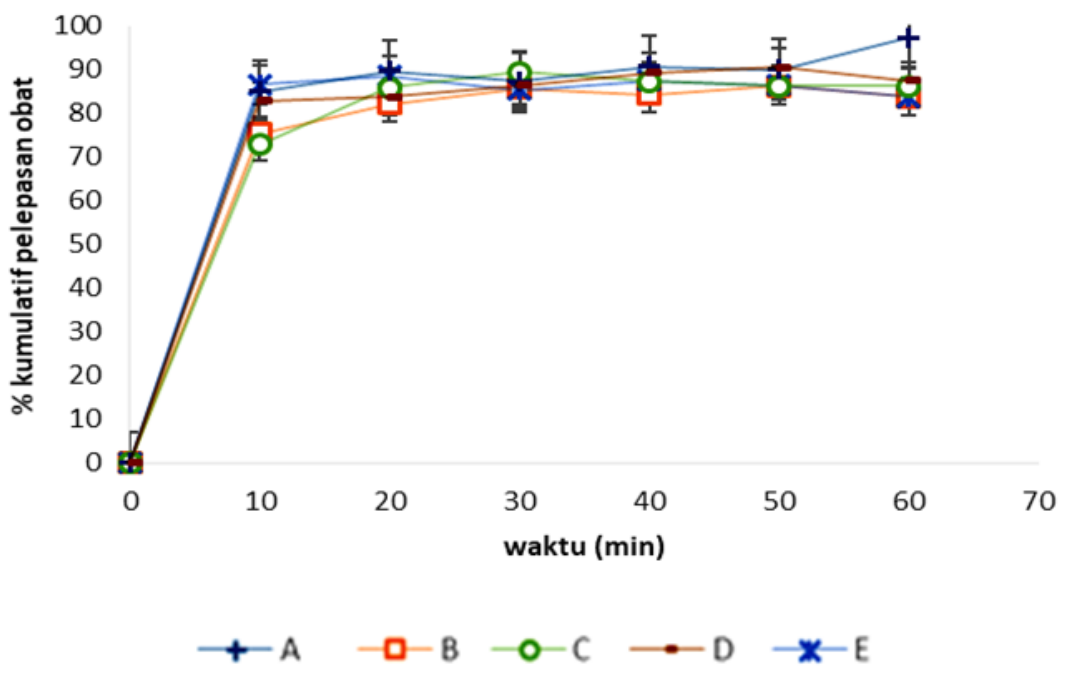

Gambar 1. Profil Disolusi Tablet Levofloksasin

tertinggi adalah 4,16 menit dan tablet dengan konsentrasi SSG terendah menghasilkan waktu hancur 6,40 menit.

\section{Kadar Levofloksasin dalam Tablet}

Hasil keseragaman kadar dapat dilihat pada Tabel III. Keseragam kadar dari tablet levofloksasin menunjukan kesesuaian dengan persyaratan kadar zat aktif, yaitu dari 10 tablet tidak ada satupun yang menyimpang dari nilai rentang kadar 90-110\% (USP 30-NF 25, 2007).

\section{Profil Disolusi Tablet Levofloksasin}

Hasil pengujian disolusi in-vitro memperlihatkan semua formula memenuhi persyaratan, yaitu pada waktu 30 menit tidak boleh $<80 \%$ levofloksasin yang terdisolusi dalam medium. Namun, perbedaan konsentrasi SSG tidak memberikan pengaruh yang kuat terhadap \%pelepasan in-vitro levofloksasin. Hal ini dapat dilihat dari hasil uji yang menunjukan bahwa Formula A dengan konsentrasi SSG 5 mg memberikan \%pelepasan yang lebih tinggi dari formula lainnya pada waktu ke-30 menit sebesar 89,59\% sedangkan Formula D dengan konsentrasi SSG tertinggi $8 \mathrm{mg}$ memberikan \%pelepasan pada waktu ke-30 menit sebesar $83,74 \%$, dan Formula C dengan konsentrasi SSG terendah $2 \mathrm{mg}$ memberikan \%pelepasan pada waktu ke-30 menit sebesar 85,81\%.

Disolusi tablet levofloksain hasil formulasi menggunakan SSG terlihat sangat baik. Hal ini disebabkan karena SSG merupakan cross-linked pati yang tersubstitusi glukosa.
Tingkat cross-linked dan substitusi menjadi faktor penting untuk menentukan efektivitas fungsi disintegrasinya. Kemampuan swelling SSG lebih baik dibandingkan disintegran yang berasal dari cross-linked PVP (swelling sangat kecil) dan cross-linked selulosa (swelling 4-8 kali) (Mohanachandran dkk., 2011). Sedangkan SSG memiliki kemampuan swelling 7-12 kali dalam waktu $<30$ detik dalam air membuat volume tablet menggembang cepat karena adanya absorpsi maksimal air dari media dengan kecepatan tinggi dan menyebabkan tablet hancur (Jaimini dkk., 2013). Setelah proses pembubaran (hancurnya tablet) maka zat aktif akan terlepas dari tablet dengan waktu yang cepat pula. Hal ini, berpengaruh terhadap peningkatan laju disolusi levofloksasin. Proses disintegrasi secara mekanis dapat dibagi menjadi 2 tahap, yaitu: 1) pembentukan agregat kasar dan 2) deagregasi selanjutnya menjadi partikel primer halus (Desai dkk., 2016).

\section{Pemodelan Kinetika Pelepasan Tablet Levofloksasin}

Hasil pemodelan kinetika pelepasan obat menggunakan model independent method dapat dilihat pada Tabel IV. Nilai rata-rata f1 dari perbandingan tiap formula masih berada pada rentang 0-15. Nilai f2 juga memperlihatkan kesamaan profil disolusi tiap formula dengan nilai f2 pada rentang 50-100. Sehingga profil disolusi tablet levofloksasin IR yang meliputi formula A, B, C, D, dan E dapat dikatakan mirip satu sama lain. 
Tabel IV. Nilai f1 dan f2 Profil Disolusi Tablet Levofloksasin

\begin{tabular}{ccccccc}
\hline Faktor & Formula & A & B & C & D & E \\
\hline Perbedaan (f1) & A & - & 7,84 & 6,72 & 3,83 & 4,59 \\
& B & 8,50 & - & 3,12 & 4,53 & 4,32 \\
& C & 7,15 & 3,06 & - & 4,45 & 4,56 \\
Perbedaan (f1) & D & 3,98 & 4,33 & 4,34 & - & 3,67 \\
& E & 4,78 & 4,15 & 4,56 & 3,68 & - \\
& A & - & 56,16 & 58,40 & 66,97 & 62,54 \\
& B & 56,16 & - & 77,43 & 69,00 & 64,55 \\
& C & 58,40 & 77,43 & - & 67,05 & 62,20 \\
& D & 66,97 & 69,00 & 67,05 & - & 73,81 \\
\hline
\end{tabular}

Tabel V. Parameter T25\%, T50\%, T80\%, dan T90\% First Order Kinetik

\begin{tabular}{cccccc}
\hline Parameter & A & B & C & D & E \\
\hline T25\% (min) & $3,29 \pm 0,5$ & $4,43 \pm 0,5$ & $3,65 \pm 1,3$ & $3,89 \pm 0,3$ & $4,20 \pm 0,2$ \\
T50\% (min) & $7,93 \pm 1,3$ & $10,68 \pm 1,3$ & $8,79 \pm 3,1$ & $9,38 \pm 0,9$ & $10,13 \pm 0,5$ \\
T80\% (min) & $18,43 \pm 3,1$ & $24,80 \pm 3,0$ & $20,41 \pm 7,3$ & $21,77 \pm 2,1$ & $23,52 \pm 1,3$ \\
T90\%(min) & $26,36 \pm 4,5$ & $35,48 \pm 4,3$ & $29,20 \pm 10,4$ & $31,15 \pm 3,0$ & $33,65 \pm 1,8$ \\
\hline
\end{tabular}

Tabel VI. Kriteria Model Kinetika Pelepasan Obat

\begin{tabular}{cclllll}
\hline Model & Kriteria & \multicolumn{1}{c}{ A } & \multicolumn{1}{c}{ B } & \multicolumn{1}{c}{ C } & \multicolumn{1}{c}{ D } & \multicolumn{1}{c}{ E } \\
\hline Zero & $\mathrm{R}^{2} \_$adj & $-0,14 \pm 0,07$ & $-0,17 \pm 0,03$ & $-0,13 \pm 0,11$ & $-0,20 \pm 0,10$ & $-0,39 \pm 0,05$ \\
order & MSE & $1345,7 \pm 100$ & $1185,1 \pm 111$ & $1192,7 \pm 50$ & $1301,5 \pm 62$ & $1500,8 \pm 121$ \\
& AIC & $64,96 \pm 0,53$ & $64,06 \pm 0,64$ & $64,13 \pm 0,29$ & $64,74 \pm 0,33$ & $65,72 \pm 0,56$ \\
& MSC & $-2,28 \pm 0,13$ & $-2,23 \pm 0,08$ & $-2,18 \pm 0,18$ & $-2,36 \pm 0,13$ & $-2,54 \pm 0,03$ \\
First & R $^{2}$ adj & $0,86 \pm 0,05$ & $0,79 \pm 0,02$ & $0,85 \pm 0,09$ & $0,81 \pm 0,07$ & $0,70 \pm 0,01$ \\
order & MSE & $158,08 \pm 51$ & $218,01 \pm 35$ & $152,91 \pm 91$ & $204,77 \pm 73$ & $322,2 \pm 16,5$ \\
& AIC & $49,72 \pm 2,43$ & $52,17 \pm 1,16$ & $48,61 \pm 5,29$ & $51,52 \pm 2,33$ & $54,96 \pm 0,36$ \\
& MSC & $-0,09 \pm 0,48$ & $-0,53 \pm 0,17$ & $0,04 \pm 0,89$ & $-0,47 \pm 0,42$ & $-1,00 \pm 0,05$ \\
Higuchi & R $^{2}$ adj & $0,63 \pm 0,04$ & $0,62 \pm 0,03$ & $0,65 \pm 0,06$ & $0,61 \pm 0,06$ & $0,48 \pm 0,03$ \\
& MSE & $432,91 \pm 50$ & $383,56 \pm 60$ & $366,17 \pm 43$ & $425,05 \pm 49$ & $553,86 \pm 61$ \\
& AIC & $57,00 \pm 0,82$ & $56,13 \pm 1,06$ & $55,83 \pm 0,82$ & $56,88 \pm, 79$ & $58,73 \pm 0,77$ \\
Hixson - & MSC & $-1,13 \pm 0,18$ & $-1,10 \pm 0,15$ & $-0,99 \pm 0,26$ & $-1,23 \pm 0,19$ & $-1,54 \pm 0,06$ \\
Crowell & R ${ }^{2}$ adj & $0,76 \pm 0,07$ & $0,66 \pm 0,03$ & $0,69 \pm 0,12$ & $0,69 \pm 0,09$ & $0,56 \pm 0,01$ \\
& MSE & $282,69 \pm 73$ & $340,52 \pm 50$ & $326,4 \pm 131$ & $330,81 \pm 84$ & $472,01 \pm 24$ \\
& AIC & $53,89 \pm 1,90$ & $55,30 \pm 1,04$ & $54,60 \pm 2,97$ & $55,01 \pm 1,69$ & $57,63 \pm 0,37$ \\
& MSC & $-0,69 \pm 0,40$ & $-0,97 \pm 0,15$ & $-0,83 \pm 0,53$ & $-0,97 \pm 0,33$ & $-1,38 \pm 0,04$ \\
\hline
\end{tabular}

Hasil pemodelan menggunakan model dependent method memperlihatkan bahwa kinetika First Order dapat lebih baik dalam menggambarkan pelepasan obat tablet levofloksasin. Semua formula yang dimodelkan dengan kinetika pelepasan First Order memberikan nilai MSE dan AIC terkecil, serta memberikan nilai $\mathrm{R}^{2}$ _adj dan MSC terbesar dibandingkan dengan model kinetika lainnya. Nilai R_2_adj, MSE, AIC, dan MSC dari masingmasing formula dapat dilihat pada Tabel VI. Hasil menunjukan bahwa formula A memiliki nilai parameter model kinetika First Order terbaik dengan nilai rata-rata $\mathrm{R}^{2}$ adj $0,86 \pm 0,05$, AIC 49,72 $\pm 2,43$, MSE 158,08 \pm 51 , dan MSC $0,09 \pm 0,48$. Hal tersebut mengindikasikan bahwa formula A memiliki nilai persen pelepasan obat antara prediksi model dengan observasi yang paling mendekati satu sama lain.

Parameter disolusi model kinetika First Order yang meliputi T25\%, T50\%, T80\%, dan T90\% memperlihatkan bahwa Formula A dengan konsentrasi disintegran SSG 5 mg pada prediksi model DD Solver memberikan 
parameter T90\% yang lebih cepat, meskipun tidak memberikan perbedaan yang signifikan dari formula lain, yaitu hampir $90 \%$ levofloksasin terdisolusi dalam waktu $<30$ menit $(26,36 \pm 4,5$ menit). Hal tersebut menunjukan bahwa kemampuan SSG memiliki batasan konsentrasi untuk memberikan fungsinya sebagai disintegran dengan optimal pada formula. Konsentrasi SSG yang semakin tinggi dalam formula akan memicu proses gelling dan dapat menghambat proses disolusi tablet (Pahwa dan Gupta, 2011).

Selanjutnya profil disolusi tiap formula dimodelkan menggunakan Korsmeyer-Peppas untuk menganalisis mekanisme pelepasanya. Formula A sampai D dapat dilakukan pemodelan sedangkan Formula E tidak dapat dimodelkan menggunakan Korsmeyer-Peppas. Model Korsmeyer-Peppas pada dasarnya dikembangkan untuk menggambarkan kinetika pelepasan obat dari matriks polimer. Model ini menerangkan mekanisme pelepasan berdasarkan persamaan Fickan dan non-Fickian dengan melihat pada nilai $\mathrm{n}$ (release exponent) (Costa dan Sousa Lobo, 2001).

Hasil pemodelan Korsmeyer-Peppas. menunjukan bahwa semua formula tablet levofloksasin memiliki nilai $\mathrm{n}<0,5$. Formula A memiliki nilai $\mathrm{n}=0,043 \pm 0,021$, Formula $\mathrm{B}$ nilai $\mathrm{n}=0,066 \pm 0,034$, Formula $\mathrm{C}$ nilai $\mathrm{n}=$ $0,087 \pm 0,039$, dan Formula $\mathrm{D}$ nilai $\mathrm{n}=$ $0,045 \pm 0,031$. Ini mengindikasikan bahwa mekanisme transport pemodelan dari tablet levofloksasin hasil formulasi mengikuti persamaan Fickian semu sehingga menggambarkan pelepasan obat dari matriks non-swellable (Singhvi dan Singh, 2011). Hal tersebut sejalan dengan penelitian ini dimana tablet levofloksasin diformulasikan Immediaterelease (IR) yang ditujukan agar cepat hancur dan terabsorpsi kedalam tubuh. Sehingga eksipien tablet dibuat tanpa menggunakan matriks polimer.

\section{KESIMPULAN}

Tablet levofloksasin IR yang diformulasikan menggunakan perbedaan jumlah disintegran SSG mengikuti model pelepasan obat First Order kinetic. Semua formula tablet levofloksasin yang dihasilkan memenuhi kriteria sifat fisik, kadar zat aktif, dan profil disolusi yang baik.

\section{UCAPAN TERIMA KASIH}

Penulis mengucapkan terimakasih kepada Fakultas Farmasi UGM yang telah memberikan bantuan dana melalui Hibah Penelitian Dasar Unggulan Tahun 2018.

\section{DAFTAR PUSTAKA}

Anonim, 2014. Farmakope Indonesia Jilid II, V. ed. Kementrian Kesehatan Republik Indonesia, Jakarta.

Bhavanam, P.R., Lekkala, V.K., Maddirala, P., Narender, S., Krishna, A.S., dan Rajesh, C., 2010. Formulation and Evaluation of Levofloxacin Using Different Types and Concentrations of Superdisintegrants. J. Pharm. Sci., 6.

Costa, P. dan Sousa Lobo, J.M., 2001. Modeling and comparison of dissolution profiles. European Journal of Pharmaceutical Sciences, 13: 123-133.

Desai, P.M., Liew, C.V., dan Heng, P.W.S., 2016. Review of Disintegrants and the Disintegration Phenomena. Journal of Pharmaceutical Sciences, 105: 25452555.

Gerber, W., Hamman, J., dan Steyn, J., 2018. Excipient-Drug Pharmacokinetic Interactions: Effect of Disintegrants on Efflux Across Excised Pig Intestinal Tissues. Journal of food and drug analysis, 26: 115-124.

Jaimini, M., Ranga, S., Kumar, A., Sharma, S., dan Chauhand, B., 2013. A Review on Immediate Release Drug Delivery System by Using Design of Experiment. Journal of Drug Discovery and Therapeutics, 1: 2127.

Mohanachandran, P.S., Sindhumol, P.G., dan Kiran, T.S., 2011. Superdisintegrants: An Overview. International Journal of Pharmaceutical Sciences Review and Research, 6: 5.

Niazi, S.K., 2004. Guidance on Formulating Compressed Solids, dalam: Handbook of Pharmaceutical Manufacturing Formulations Compressed Solid Products. CRC Press LLC, Washington, D.C.

Paarakh, M.P., Jose, P.A., Setty, C., dan Peter, G.V., 2018. Release Kinetics - Concepts and Applications. International Journal of Pharmacy Research \& Technology, 8: 9.

Pahwa, R. dan Gupta, N., 2011. 
Superdisintegrants in the Development of Orally Disintegrating Tablets: A Review. International Journal of Pharmaceutical Sciences and Research, 2: 14.

Qureshi, M.S., Zafar, F., Ali, H., Hameed, K., Mallick, N., Khan, S., dkk., 2016. Superdisintegrant on Disintegrant and Dissolution. The Professional Medical Journal, 23: 1167-1170.

Ramteke, K.H., Dighe, P.A., Kharat, A.R., dan Patil, S.V., 2014. Mathematical Models of Drug Dissolution: A Review. Sch. Acad. J. Pharm., 3: 388-396.
Singhvi, G. dan Singh, M., 2011. In-Vitro Drug Release Characterization Models. Int J Pharm Stud Res, 2: 77-84.

Todorović, N., Goločorbin-Kon, S., Kermeci, K.N., Jovičić Bata, J., Pavlović, N., Milijašević, B.Ž., dkk., 2018. Influence of Immediate Release Tablet Formulation on Dissolution Profi le of Paracetamol. Hospital Pharmacology, 5: 705-714.

USP 30-NF 25, 2007. The United States Pharmacopoeial Convention. The official compendia of standards Copyright 2006.

Zhang, Y., Huo, M., Zhou, J., Li, W., Yao, C., dan Xie, S., 2010. DD solver: An Add-in Program for Modeling and Comparison of Drug Dissolution Profiles. AAPS J., 12: 263. 